\title{
BMJ Open Social and territorial inequalities in breast and cervical cancers screening uptake: a cross-sectional study in France
}

\author{
Lisa Ouanhnon (1) , ${ }^{1,2}$ Marie-Eve Rougé Bugat, ${ }^{1,2}$ Sebastien Lamy, ${ }^{2,3}$ \\ Vladimir Druel, ${ }^{1,2}$ Cyrille Delpierre, ${ }^{2,4}$ Pascale Grosclaude ${ }^{2,3}$
}

To cite: Ouanhnon L, Rougé Bugat M-E, Lamy S, et al. Social and territorial inequalities in breast and cervical cancers screening uptake: a cross-sectional study in France. BMJ Open 2022;12:e055363. doi:10.1136/ bmjopen-2021-055363

- Prepublication history and additional supplemental materia for this paper are available online. To view these files, please visit the journal online (http://dx.doi.org/10.1136/ bmjopen-2021-055363)

CD and PG contributed equally

Received 13 July 2021 Accepted 04 January 2022

\section{A) Check for updates}

(c) Author(s) (or their employer(s)) 2022. Re-use permitted under CC BY-NC. No commercial re-use. See rights and permissions. Published by BMJ.

${ }^{1}$ DUMG (Département Universitaire de Médecine Générale), Université Toulouse III Paul Sabatier, Toulouse, France ${ }^{2}$ CERPOP, INSERM UMR_S 1027, Toulouse, France

${ }^{3}$ Registre des cancers du Tarn, Institute Claudius Regaud,

Toulouse, France

${ }^{4}$ LEASP, Université Toulouse III

Paul Sabatier, Toulouse, France

Correspondence to

Dr Lisa Ouanhnon;

lisa.ouanhnon@gmail.com

\section{ABSTRACT}

Objective The objective of this cross-sectional study was to investigate the impact of socio-territorial characteristics on mammography and pap smear uptake according to the place of residence in the recommended age groups, and second outside the recommended age groups.

Setting and participants We used an existing dataset of 1027039 women which combines data from the Health Insurance information systems, with census data from Midi-Pyrénées, France.

Primary and secondary outcome measures Our outcome was, for each woman, the uptake of the pap smear and the uptake of the mammography during the year.

Results A social gradient of screening uptake was found in the recommended age groups. This gradient was stronger in large urban areas:

(1) For mammography: decile 10 (the most deprived) vs 1 (the least deprived), adjusted OR $0.777,95 \% \mathrm{Cl}(0.748$ to 0.808 ) in large urban area; adjusted $\mathrm{OR}=0.808$ for decile 1 to 0.726 for decile 10 in other areas vs decile 1 in urban areas;

(2) For pap smear: decile 10 vs 1 adjusted $0 \mathrm{R} 0.66,95 \% \mathrm{Cl}$ ( 0.642 to 0.679 ) in large urban areas; adjusted $\mathrm{OR}=0.747$ for decile 1 to 0.562 for decile 10 in other areas vs decile 1 in urban areas).

Screening rates were globally higher in large urban areas. For mammography, the social and territorial disparities were higher outside the recommended age group. Conclusions Offering a universal approach to every woman, as it is often the case in nationally organised screening programmes, is likely to be insufficient to ensure real equity in access. Developing global dataset combining health data and diverse socioeconomic data, at individual and contextual levels, could enable a better understanding of the mechanisms involved in this social gradient, and therefore, the development of targeted territorial actions to improve equity of access to healthcare.

\section{INTRODUCTION}

Breast and cervical cancers are among the most frequent cancers in women worldwide. They kill more than 600000 and 300000 women, respectively, every year. ${ }^{1}$

For breast cancer in France, through the nationally organised screening programme, all women between 50 and 74 years old are

\section{Strengths and limitations of this study}

The use of health insurance data, merged with socioterritorial information, allowed for a very powerful and comprehensive study on social inequalities in health (database of 2.5 million of individuals or $88 \%$ of the region's total population).

- We used both individual and contextual variables to investigate the link between an ecological deprivation index and breast and cervical cancers screening.

- We performed a sequential regression (variables were successively added in the multivariable model) to investigate the role of each variable in the link between the ecological deprivation index and screening and studied the interaction between EDI and the type of place of residence.

- Our data covered only 1 year and we had a limited number of individual and contextual variables in our dataset.

offered a mammography every 2 years. $^{2}$ For cervical cancer, a national screening programme is progressively being implemented. ${ }^{3}$ Before 2018, guidelines recommended a pap smear every 3 years between 25 and 65 years old.

In France, the participation rate is around $50 \%$ for breast cancer screening and $60 \%$ for cervical cancer. ${ }^{4}$ Despite an universal health coverage policy, mammography and pap smear uptake, and therefore, breast and cervical cancer survival, vary considerably with factors like socioeconomic position (SEP) and place of residence. ${ }^{5-8}$ This raises the question of the determinants of universal access, in particular physical accessibility (availability, reasonable reach), financial affordability (healthcare cost, transportation, time away from work) and sociocultural accessibility (perceived effectiveness, social and cultural factors) ${ }^{910}$ All these dimensions may be socially distributed and partly explain the inequalities of screening uptake. 
Disentangling underlying mechanisms leading to these inequalities is a first step to address them. However, further studies on this topic have been made difficult by the lack of large and representative dataset combining socioeconomic, territorial and healthcare data. ${ }^{11}$

We used French healthcare insurance reimbursement data, merged with socioterritorial information, to assess and investigate the influence of deprivation on mammography and pap smear uptake, according to the place of residence, in the recommended age groups and second outside the recommended age groups. To this end, we investigated the role of variables indicating financial precarity, healthcare accessibility and adherence to the healthcare system.

\section{METHODS}

\section{Study design}

We used a dataset combining data from health insurance information systems with census data, based on the address of residence. This dataset has been described in detail elsewhere. ${ }^{12}$

The health data was prospectively collected by the three main health insurance providers for 2012.

\section{Population}

This dataset included individuals who were beneficiaries of any of the three health insurance providers on the 31 December 2012 in Midi-Pyrénées. The individuals with an incomplete address or with differences in the management of their data were excluded. We obtained a base of $2,574,310$ subjects ( $88 \%$ of the region's total population).

For this study, we focused on women over 20 years old (1 027039 women), as cancers screening is rarely offered to women below that age.

\section{Patient and public involvement}

Patients or the public were not involved in the design of our study.

\section{Collected variables \\ Main outcomes}

Our outcome was, for each woman, the uptake of the pap smear and the uptake of the mammography. It was categorised as a binary variable for each screening test to discriminate the women who had at least one mammography/pap smear during the year, and the other ones. Regarding mammography, we only included screening exams, but we could not differentiate between opportunistic and organised screening.

\section{Main explanatory variables}

In the absence of individual social data, social condition of the participants was approached by an ecological deprivation index, the European Deprivation Index. ${ }^{13}$ The EDI approaches SEP by measuring social deprivation as defined by Townsend as 'a state of observable and demonstrable disadvantage relative to the local community or the wider society to which an individual, family or group belongs'. To calculate the EDI, we used the aggregated unit for statistical information ('IRIS') corresponding to the person's address. IRIS is the smallest geographical unit for which statistics are available in France, which represents about 2000 inhabitants. Each IRIS was assigned an EDI value, calculated with census data. We used an EDI presentation in deciles, calculated from all the IRISs of the region: decile 1 corresponds to the least deprived zones, decile 10 to the most deprived zones.

\section{Covariates}

We considered age as a potential confounder. As the association between this variable and the outcomes clearly appeared non-linear, we categorised it (into 5-year groups).

As an ecological index of deprivation, EDI is assumed to be capturing both intrinsic properties of the individuals in the area and contextual properties of the area. ${ }^{14}$ To explore the mechanisms involved in the link between EDI and screening uptake, we chose to study various factors, including one individual and one contextual:

- The Supplementary Universal Healthcare Coverage (CMU-C) is offered to individuals who earn less than a defined income threshold, to pay for their healthcare expenses. This characteristic was used as a proxy for individual financial precarity. Our hypothesis was that financial precarity, by limiting financial accessibility, was key in the link between deprivation and screening participation.

- Healthcare supply is a contextual property influencing deprivation. We assumed that this factor could partly explain the link between EDI and screening uptake by measuring physical accessibility. Healthcare supply at IRIS level was approached by the Potential Localised Accessibility (PLA) to the general practitioner (GP). The PLA calculates the distanceweighted supply and the local demand, measured by the age-differentiated rate of access. It is interpreted as a medical density (number of full-time equivalents for 100000 inhabitants). ${ }^{15}$

We assumed that the overall healthcare system adherence could also explain part of the association between deprivation and screening uptake. Therefore, we used a binary variable that discriminates between the patients who had no designated referring physician (in most cases a GP) and the ones who had one. This health-seeking behaviour is a property of individuals but is likely to be influenced by both individual and contextual factors. ${ }^{16}$

Healthcare supply and transport facilities are very different in rural and urban areas. ${ }^{17-19}$ We assumed that the level of urbanisation of the place of residence could modify the social gradient of screening uptake. Based on the French National Institute of Statistics and Economic Studies's 2010 zoning in urban areas, we built a variable to distinguish the large urban centres (more than 10000 jobs) and their suburbs (urban units in which at least $40 \%$ of the active residents work in the urban centre or in the towns attracted by it), ${ }^{20}$ from the rest of the region. In the 


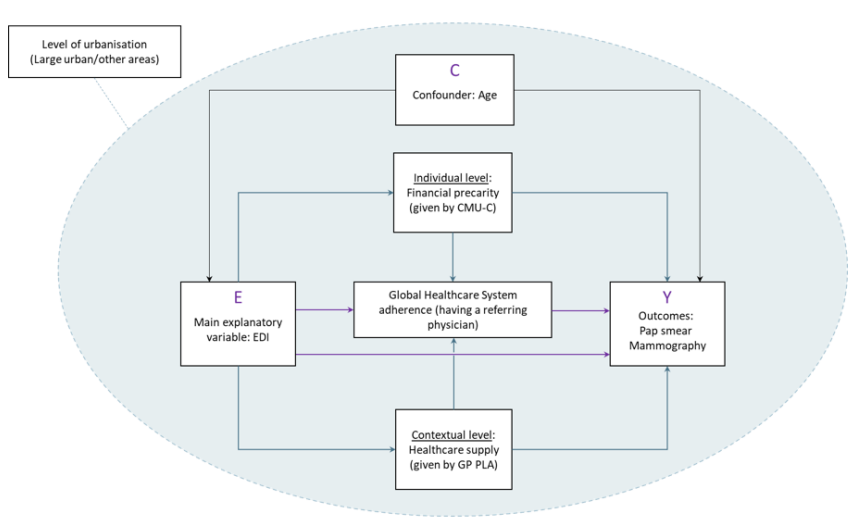

Figure 1 Conceptual model. Links between the studied variables assumed to explain the impact of deprivation on screening uptake, depending on the level of urbanisation. EDI, European Deprivation Index; CMU-c, Couverture Médicale Universelle-Complémentaire (Supplementary Universal Healthcare Coverage); GP, General Practitioner; PLA, Potential Localised Accessibility.

descriptive analysis, we differentiated among large urban areas between Toulouse metropolis, the regional capital which covers almost a quarter of the region's population, and the other areas.

Our conceptual model showing how these variables interact is presented in figure 1.

\section{Statistical analysis}

To describe the sample, we performed univariate analyses: we tested the association between the main explanatory variable and the outcomes, between each covariate and the outcomes, and between each covariate and the EDI.

We used a multivariable logistic regression model to analyse the association between EDI and the mammography and pap smear uptake, adjusted for all the previously identified confounders and intermediate variables. We performed a sequential regression. The variables were successively added to the model following a predefined order: the main explanatory variable alone first, then the confounder, and lastly the intermediate variables (at an individual then at a contextual level).

We studied the interaction between EDI and the type of place of residence (large urban/other areas) in the model through a new variable: a 20-modal indicator with ten modalities (corresponding to the EDI deciles) per type of geographical area.

We undertook some age groups analyses to study women outside the recommended age groups (younger and older). For younger women, we focused on women aged 20-25 for pap smear and 40-50 for mammography. Our hypothesis was that social and territorial inequalities were higher for women outside the recommended age groups.

Since we used data that are systematically recorded by health insurance providers, we expected very little missing data. This was, therefore, negligible in light of the global sample size (around 0.01\%): a complete case analysis could be used.

Statistical analyses were performed with $\mathrm{R}$ software ( $\mathrm{R}$ V.64 3.0.2). ${ }^{21}$

\section{RESULTS}

Selected population in the recommended age groups for mammography (50-74 years old) and pap smear (25-65 years old), were composed of 365947 and 711803 women respectively (table 1 ). Among these women, $31 \%$ had had at least one mammography during the year, and $29 \%$ at least one pap smear. Almost two-thirds of the population lived in large urban areas. A major part of the most disadvantaged women lived in the Toulouse metropolis (online supplemental tables A). Around 8\% of the 25-65 women and less than $4 \%$ of the 50-74 had the CMU-C. $92 \%$ of the 25-65 women and $95 \%$ of the 50-74 had a designated referring physician.

The more deprived the area of residence, the lower the breast and cervical cancers screening uptakes $(p-<0.001)$ (table 1). Regarding age, the mammography rate seemed rather constant throughout the recommended ages. Pap smear uptake decreased a lot after 55 years old (from $31 \%$ to $23 \%$ between the $45-50$ and the $55-60$ years old groups). Women with CMU-C had a lower screening uptake rate. We noticed a slight territorial gradient: the higher the GP density, the higher the mammography and pap smear uptake, except for the last two deciles. The women living in large urban areas had a higher screening rate than the ones living in the rest of the region. Women who had a designated referring physician had a higher screening rate $(32 \%$ vs $5 \%$ for mammography, $31 \%$ vs $8 \%$ for pap smear, $\mathrm{p}<0.001)$.

Adding the interaction term between EDI and the type of place of residence (large urban/other areas) improved our models (better likelihood, $\mathrm{p}=0.0048$ for mammography uptake and 0.0040 for pap smear uptake). figures 2 and 3 present the logistic regression of mammography and pap smear uptake in the recommended age groups: first the ORs associated with the variable combining EDI and the type of place of residence (large urban/other areas), then the result of the sequential adjustments, and lastly the final multivariable regression model.

For mammography (figure 2), an effect of European Depriivation Index (EDI) on mammography uptake was observed, through a social gradient: the screening uptake regularly decreased with increasing deprivation. This social gradient was mostly observed in large urban areas (decile 10 vs 1 adjusted OR $0.777,95 \%$ CI $(0.748$ to 0.808$))$. The social gradient was less strong in the other areas, where mammography rate was globally lower than in urban areas. Influence of financial precarity was corroborated by CMU-C impact on screening uptake (adjusted OR $0.644,95 \%$ CI (0.618 to 0.671$)$ ). The territorial gradient based on GP accessibility was confirmed. Adding this variable decreased only slightly the difference 
Table 1 Sociodemographic characteristics of women

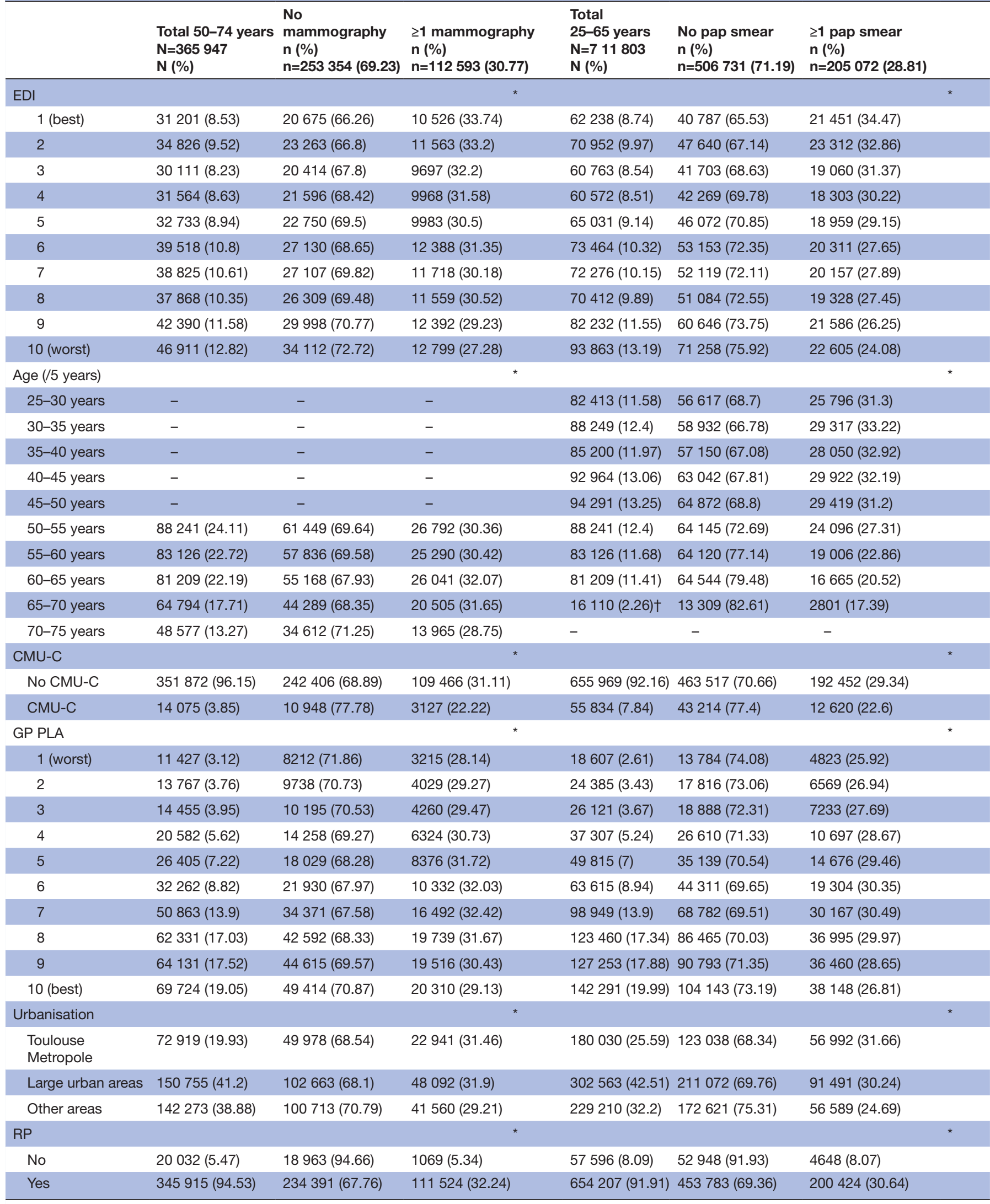

${ }^{*} \mathrm{P}<0.001$

†Only 65 years women

CMU-c, Couverture Médicale Universelle-Complémentaire (Supplementary Universal Healthcare Coverage);; EDI, European Deprivation Index; GP, General

Practitioner; PLA, Potential Localised Accessibility; RP, Referring Physician. 


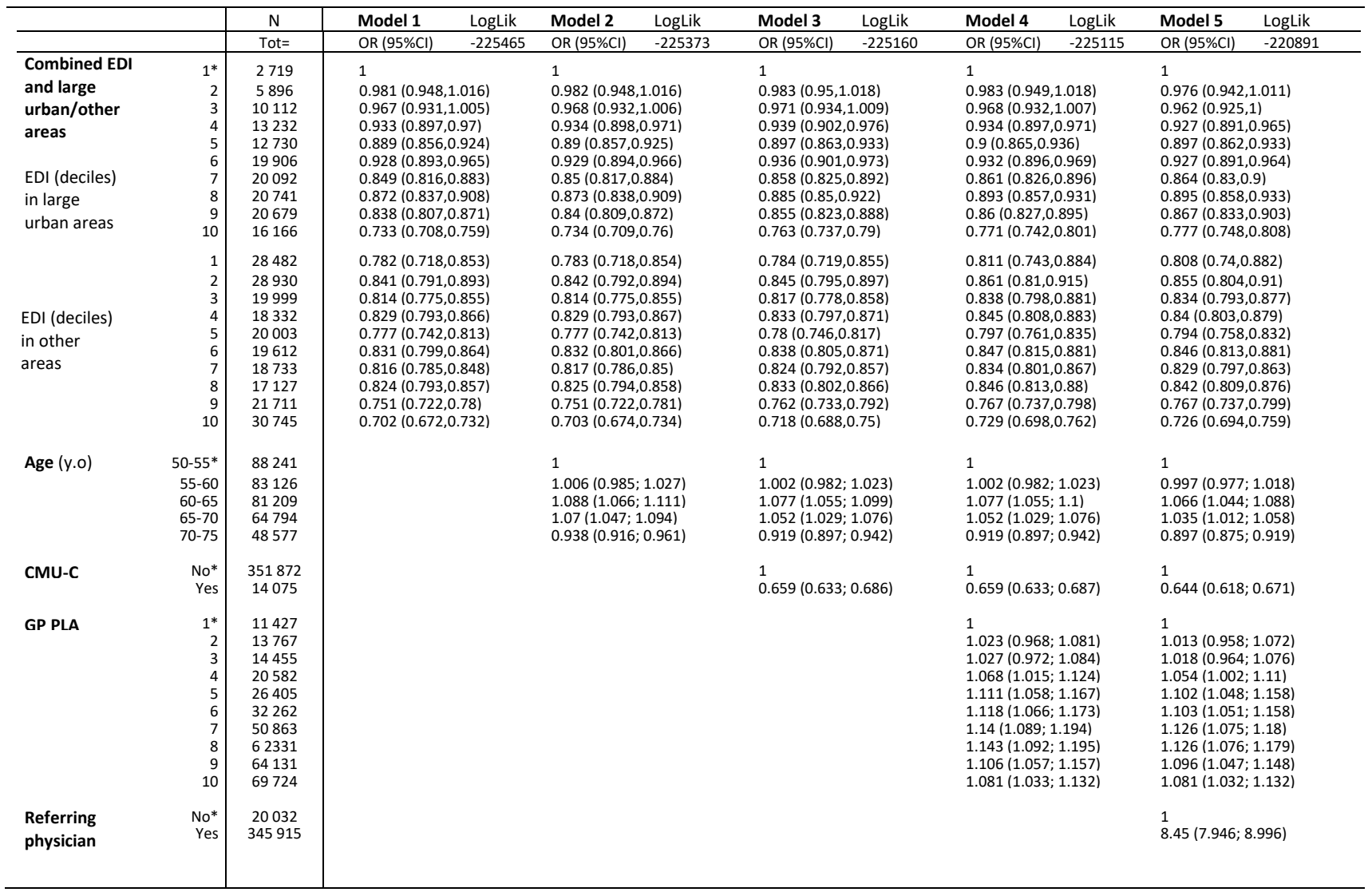

Figure 2 Mammography uptake in recommended age group: multivariable logistic regression models (mammography uptake $=30.77 \%$ ).

${ }^{*}$ Reference category.

CMU-c, Couverture Médicale Universelle-Comprélmentaire (Supplementary Universal Healthcare Coverage); EDI, European Deprivation Index; GP, general practitioner; PLA, potential localised accessibility.

between large urban and other areas. The link between mammography and having a designated referring physician was confirmed as well (adjusted OR 8.45, 95\% CI (7.946 to 8.996)). Age had a very limited effect on mammography uptake. Sequential inclusion of all these variables in the model modified only slightly the link between EDI and screening uptake.

For pap smear (figure 3), a strong social gradient was observed. This gradient was slightly stronger in large urban areas (decile 10 vs 1 adjusted OR $0.66,95 \%$ CI $(0.642$ to 0.679$))$ than in the rest of the region (adjusted $\mathrm{OR}=0.747$ for decile 1 to 0.562 for decile 10 in other areas vs decile 1 in urban areas). Influence of financial precarity was corroborated by CMU-C impact on screening uptake (adjusted $\mathrm{OR}=0.669$ ). The territorial gradient (based on GP accessibility) was confirmed but, as for mammography, adding this variable decreased only slightly the difference between large urban and other areas. The multivariable analysis confirmed the association between having a designated referring physician and pap smear uptake (adjusted OR 5.39 95\% CI (5.227 to 5.557)). An effect of age on pap smear uptake was also found (adjusted OR
$0.59,95 \%$ CI $(0.574$ to 0.601$)$ for $55-60$ years old women vs 25-30 women). Sequential inclusion of all these variables in the model modified only slightly the link between EDI and screening uptake.

We used the same approach for women outside the recommended age groups (figure 4 and online supplemental table B). Among younger women (40-50 years old for mammography and 20-25 for pap smear), both mammography and pap smear uptakes in the year were around 21\%. Among women older than the recommended age, participation rates were around $6 \%$ for both breast and cervical cancers. Figure 4 shows that the social gradient in mammography uptake was substantially stronger in women between the ages of 40 and 50 , and more so in large urban areas. For pap smear uptake, social gradient seemed less strong in younger women. Regarding GP accessibility, we observed a stronger territorial gradient for older women, for both screening uptakes. 


\begin{tabular}{|c|c|c|c|c|c|c|c|c|c|c|c|c|}
\hline & & $\mathrm{N}$ & Model 1 & LogLik & Model 2 & LogLik & Model 3 & LogLik & Model 4 & LogLik & Model 5 & LogLik \\
\hline & & Total $=711803$ & OR $(95 \% \mathrm{Cl})$ & -424737 & OR $(95 \% \mathrm{Cl})$ & -420964 & OR $(95 \% \mathrm{Cl})$ & -420368 & OR $(95 \% \mathrm{Cl})$ & -420310 & OR $(95 \% \mathrm{Cl})$ & -411557 \\
\hline Combined & $1 *$ & 4741 & \multicolumn{2}{|c|}{1} & \multicolumn{2}{|l|}{1} & \multicolumn{2}{|c|}{1} & \multicolumn{2}{|c|}{1} & \multicolumn{2}{|l|}{1} \\
\hline EDI and large & 2 & 9906 & \multirow{2}{*}{\multicolumn{2}{|c|}{$0.945(0.923,0.968)$}} & & \multicolumn{2}{|c|}{$0.939(0.917,0.962)$} & \multicolumn{2}{|c|}{$0.929(0.907,0.952)$} & \multicolumn{2}{|c|}{$0.922(0.899,0.945)$} \\
\hline urban/other & 3 & 16889 & & & \multirow{2}{*}{\multicolumn{2}{|c|}{$\begin{array}{l}0.902(0.879,0.927) \\
0.878(0.854,0.902)\end{array}$}} & \multicolumn{2}{|c|}{$0.908(0.884,0.932)$} & \multicolumn{2}{|c|}{$0.897(0.873,0.921)$} & \multicolumn{2}{|c|}{$0.889(0.865,0.913)$} \\
\hline \multirow{3}{*}{ areas } & 4 & 21643 & \multicolumn{2}{|c|}{$\begin{array}{l}0.918(0.894,0.942) \\
0.887(0.863,0.912)\end{array}$} & & & \multirow{2}{*}{\multicolumn{2}{|c|}{$\begin{array}{l}0.886(0.862,0.91) \\
0.826(0.804,0.848)\end{array}$}} & \multirow{2}{*}{\multicolumn{2}{|c|}{$\begin{array}{l}0.878(0.854,0.903) \\
0.817(0.795,0.839)\end{array}$}} & $0.873(0.849$ & $0.898)$ \\
\hline & 5 & 20561 & \multicolumn{2}{|c|}{$0.833(0.811,0.855)$} & \multicolumn{2}{|c|}{$0.816(0.795,0.838)$} & & & & & $0.816(0.794$ & $0.839)$ \\
\hline & 6 & 31816 & $0.793(0.772$ & $0.815)$ & $0.781(0.76$, & & $0.792(0.77$ & & $0.78(0.759$, & 802) & $0.781(0.759$ & $0.803)$ \\
\hline EDI (deciles) & 7 & 31628 & $0.801(0.78$, & $.823)$ & $0.788(0.766$ & & $0.8(0.778,0$ & & $0.791(0.76$ & D.813) & $0.805(0.782$ & $0.828)$ \\
\hline in large urban & 8 & 32394 & $0.806(0.784$ & $0.829)$ & $0.788(0.766$ & & $0.806(0.78$ & & $0.801(0.778$ & $0.824)$ & $0.81(0.787$, & $.834)$ \\
\hline In large urban & 9 & 33163 & $0.735(0.716$ & $0.754)$ & $0.716(0.698$ & & $0.738(0.71$ & & $0.729(0.70$ & $0.749)$ & $0.748(0.727$ & $0.769)$ \\
\hline area & 10 & 26469 & $0.616(0.601$ & $0.631)$ & $0.602(0.588$ & & $0.643(0.62$ & & $0.636(0.615$ & 0.653) & $0.66(0.642$, & $.679)$ \\
\hline & 1 & 57497 & $0.723(0.678$ & 0.773) & $0.735(0.688$ & 85) & $0.737(0.69$ & & $0.749(0.70$ & D.801) & $0.747(0.699$ & ,0.799) \\
\hline & 2 & 61046 & $0.703(0.671$ & $0.738)$ & $0.72(0.686$, & & $0.724(0.69$ & & $0.731(0.69$ & 0.767) & $0.732(0.697$ & $0.768)$ \\
\hline & 3 & 43874 & $0.685(0.659$ & $0.711)$ & $0.704(0.677$ & & $0.707(0.68$ & & $0.715(0.688$ & $.744)$ & $0.716(0.689$ & $0.745)$ \\
\hline EDI (deciles) & 4 & 38929 & $0.667(0.644$ & $0.69)$ & $0.684(0.661$ & 09) & $0.69(0.666$ & & $0.693(0.665$ & 0.718) & $0.693(0.669$ & $0.718)$ \\
\hline in other area & 5 & 44470 & $0.628(0.606$ & $0.651)$ & $0.645(0.623$ & & $0.65(0.627$ & & $0.655(0.63$ & $0.679)$ & $0.659(0.635$ & $0.683)$ \\
\hline In other area & 6 & 41648 & $0.608(0.59$, & .627) & $0.626(0.607$ & & $0.632(0.61$ & & $0.631(0.61)$ & .651) & $0.637(0.617$ & $0.657)$ \\
\hline & 7 & 40648 & $0.619(0.6,0$ & 638) & $0.637(0.618$ & & $0.647(0.62$ & & $0.646(0.62$ & $0.666)$ & $0.648(0.628$ & $0.669)$ \\
\hline & 8 & 38018 & $0.591(0.574$ & $0.61)$ & $0.61(0.591$, & & $0.621(0.60$ & & 0.62 (0.601, & 64) & $0.622(0.603$ & ,0.642) \\
\hline & 9 & 49069 & $0.559(0.542$ & $0.577)$ & $0.573(0.556$ & & $0.588(0.57$ & & $0.582(0.56$ & .601) & 0.59 (0.571, & $.609)$ \\
\hline & 10 & 67394 & $0.524(0.506$ & $0.542)$ & $0.533(0.516$ & & $0.556(0.53$ & & $0.552(0.53$ & $0.572)$ & $0.562(0.542$ & $0.582)$ \\
\hline Age (y.o) & $25-30 *$ & 82413 & & & 1 & & 1 & & 1 & & 1 & \\
\hline & $30-35$ & 88249 & & & $1.084(1.062$ & 106) & $1.08(1.059$ & & 1.081 & 1.104) & 1.06 (1.038; & 1.082) \\
\hline & $35-40$ & 85200 & & & $1.063(1.042$ & 085) & $1.056(1.03$ & 078) & $1.057(1.03$ & 1.079) & $1.021(1 ; 1.0$ & \\
\hline & $40-45$ & 92964 & & & 1.031 (1.01; & & $1.021(1 ; 1$ & & $1.021(1.00$ & 1.042) & $0.963(0.944$ & ;0.984) \\
\hline & $45-50$ & 94291 & & & $0.988(0.968$ & 008) & $0.975(0.95$ & 995) & $0.975(0.95$ & $0.996)$ & $0.906(0.888$ & ; 0.925$)$ \\
\hline & $50-55$ & 88241 & & & $0.826(0.809$ & 843) & $0.811(0.79$ & 828) & $0.812(0.79$ & 0.829 ) & $0.749(0.733$ & ;0.765) \\
\hline & $55-60$ & 83126 & & & 0.655 (0.64; & & $0.641(0.62$ & 655) & $0.641(0.62)$ & $0.656)$ & $0.587(0.574$ & ; 0.601) \\
\hline & $60-65$ & 81209 & & & $0.573(0.56$; & & $0.558(0.54$ & & $0.558(0.54$ & 0.571 ) & $0.507(0.496$ & ;0.519) \\
\hline & 65 & 16110 & & & $0.468(0.448$ & 488) & $0.454(0.43$ & 474) & $0.454(0.435$ & $0.474)$ & $0.413(0.395$ & ;0.431) \\
\hline CMU-C & No* & 655969 & & & & & 1 & & 1 & & 1 & \\
\hline & Yes & 55834 & & & & & $0.696(0.68$ & 711) & $0.695(0.68$ & $0.71)$ & $0.669(0.655$ & ;0.684) \\
\hline GP PLA & & & & & & & & & & & & \\
\hline (deciles) & $1^{*}$ & 18607 & & & & & & & 1 & & 1 & \\
\hline & 2 & 24385 & & & & & & & $0.966(0.925$ & 1.01) & $0.951(0.909$ & ;0.994) \\
\hline & 3 & 26121 & & & & & & & $0.982(0.94$ & 1.026) & 0.97 (0.928; & 1.013) \\
\hline & 4 & 37307 & & & & & & & $1.004(0.965$ & 1.046) & 0.989 (0.95; & 1.031) \\
\hline & 5 & 49815 & & & & & & & 1.01 (0.971; & $.05)$ & $0.991(0.952$ & ; 1.03) \\
\hline & 6 & 63615 & & & & & & & $1.033(0.99$ & 1.073) & $1.017(0.978$ & ; 1.056) \\
\hline & 7 & 98949 & & & & & & & 1.049 (1.01) & 1.088) & $1.031(0.993$ & ; 1.069) \\
\hline & 8 & 123460 & & & & & & & $1.086(1.04$ & 1.126) & 1.068 (1.03; & $1.108)$ \\
\hline & 9 & 127253 & & & & & & & $1.056(1.018$ & 1.095) & $1.046(1.009$ & ; 1.086) \\
\hline & 10 & 142291 & & & & & & & $1.03(0.993$; & $.069)$ & $1.049(1.011$ & ;.088) \\
\hline Referring & No* & 57596 & & & & & & & & & 1 & \\
\hline physician & Yes & 654207 & & & & & & & & & $5.389(5.227$ & ;5.557) \\
\hline
\end{tabular}

Figure 3 Pap smear uptake multivariable logistic regression models in recommended age group (Pap smear uptake=28.81\%). ${ }^{*}$ Reference category.

CMU-c, Couverture Médicale Universelle-Comprélmentaire (Supplementary Universal Healthcare Coverage); EDI, European Depriivation Index; GP, general practitioner; PLA, potential localised accessibility

\section{DISCUSSION}

Our study highlighted a link between deprivation and breast and cervical cancers screening uptake, in and outside the recommended age groups. This link follows a social gradient across all socioeconomic levels. The gradient was stronger in large urban areas. The successive inclusion of variables indicating financial precarity, healthcare accessibility and adherence to the healthcare system decreased only very slightly the association, suggesting that these variables explain a very limited extent of the link between EDI and screening uptake. The social and territorial disparities in mammography uptake were lower in the recommended age group than outside.

The main strength of our study is its power and comprehensiveness, achieved by using health insurance data. Using both individual and contextual variables to investigate the link between an ecological deprivation index and screening uptake is original. Another original aspect is the exploration of screening uptake outside the recommended age groups and the observation of two different implementation modes for national recommendations (with and without a screening programme).
Our study also has limitations. As our data covered only 1 year, we could not differentiate between women who had screening tests every year (more often than recommended) and the ones who had it every 2 and 3 years as recommended. It raises the question of excess screening and its link with SEP. In our dataset, pap smears prescribed for diagnostic purposes could not be distinguished from those performed in a screening context. The limited number of individual and contextual variables in our dataset restrained our capability to disentangle what could be explained by contextual and individual properties in the associations we observed with EDI. The same difficulty limited the exploration of financial, physical and sociocultural accessibility mechanisms involved in the social gradient.

We complemented existing literature on social inequalities in access to mammography and pap smear. The link between deprivation and screening participation was found in numerous countries all over the word, irrespective of the local healthcare policy. In the USA, where no centrally organised cancer screening programme exists, this link was repeatedly reported at an individual and at 


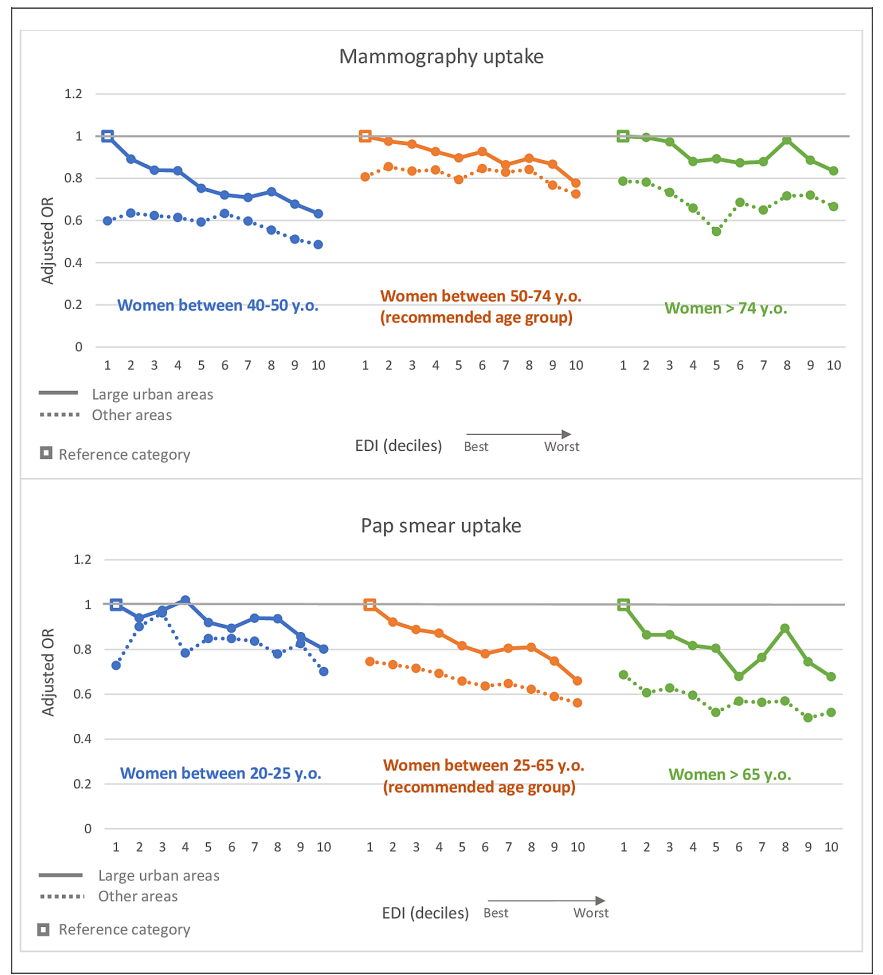

Figure 4 Mammography and pap smear uptake and combined variable EDI in large urban/other areas by age group, MIDI Pyrénées region, 2012. Results from a logistic model adjusted for EDI by age, CMU-C, GP PLA, having an official referring physician. Data from models 5 (figures 2 and 3) for the recommended age groups.

EDI, European Deprivation Index; CMU-c, Couverture Médicale Universelle-Complémentaire (Supplementary Universal Healthcare Coverage); GP, General Practitioner; PLA, Potential ILcalised Accessibility.

an area levels. ${ }^{22-25}$ In most Western European countries, nationally organised screening programmes are in place. The studies conducted there also showed an impact of SEP. ${ }^{26-28}$ In France, the lack of individual socioeconomic variable in healthcare datasets has made it difficult to obtain large and representative evidence. A few cohort studies have been conducted, but were limited by the relatively small sample size. ${ }^{72930}$ Using healthcare insurance reimbursement data merged with sociodemographic information made it possible to assess the impact of socioterritorial inequalities in larger studies, more representative of the French population. ${ }^{31}$

Our study tried to identify some of the mechanisms involved in the link between deprivation and screening uptake. One of our hypotheses was that deprivation leads to limitations of the three dimensions of healthcare accessibility: financial, physical and sociocultural. We used CMU-C to explore the effect of financial precarity in the link between deprivation and screening uptake and GP PLA, a proxy for healthcare supply, to reflect physical accessibility. Our result suggests that the association between deprivation and screening uptake is very slightly influenced by these variables. This could be due to the choice of variables used in our model. CMU-C may not be enough precise to measure financial accessibility. GP PLA is a good proxy for physical accessibility to primary care, but maybe not to specialty care. Regarding sociocultural accessibility, no truly relevant variable was available in our dataset. Our results showed that the overall adherence to the healthcare system, approached by having a referring physician, only modified slightly the link between EDI and screening uptake. However sociocultural accessibility covers several concepts. Using psychological models, R. Crockett explained that the most deprived people focus more on present time. ${ }^{32}$ They concentrate on the inconvenience of the screening rather than on the possible longterm benefits. A measure of this mechanism, the fear of the result, language barriers or cultural representations ${ }^{33}$ could be better proxies for sociocultural accessibility.

However, our study suggests that having a referring physician has a substantial direct impact on pap smear and mammography uptake. This key role of primary care providers was observed in other countries, like the USA and Canada. ${ }^{34} 35$ The improvement in screening uptake in people with a referring physician could be due to the direct role of the physician in overcoming the barriers to screening. This result might also be explained by another phenomenon linked to healthcare access: the patient's understanding of and capacity to navigate the healthcare system.

We confirmed territorial disparities in screening access. Large urban areas had higher participation rates than the rest of the region. These rural/urban disparities were observed in several studies in Western Europe and North America. ${ }^{17-19283637}$ The social gradient also appeared generally stronger in large urban areas. But even in the other areas, the most deprived populations had a lower screening access. These results corroborate the assumption that the social gradient is stronger if the healthcare supply is sufficient, but access to care of the most deprived remains lower whatever the place.

We observed that the social and territorial disparities in mammography uptake were lower inside the recommended age group than for younger women. We did not observe the same trend for pap smear uptake. This difference could be explained by the nationally organised screening programme in place for breast cancer at the time of data collection but not for cervical cancer. Some studies suggested that tools used in the breast cancer screening programme might help decrease inequalities of access, ${ }^{38} 39$ but other showed that a national programme, with the exact same actions for every women, while improving overall participation rates, could also increase the social gradient in uptake. ${ }^{40}$ Pap smear and mammography uptake also appeared very high in women younger than the recommended age. While the social gradient within the recommended age groups is likely to be explained by a low uptake in deprived populations, its existence among younger and older women may indicate an overuse of screening in high SEP populations. ${ }^{41}$ Regarding women older than the recommended age, we observed a higher effect of territorial disparities on 
screening uptake (rural/urban disparities and effect of GP accessibility). This suggests that older women could have more difficulty adapting to territorial barriers.

Developing global dataset combining health data and diverse socioeconomic data, at individual and contextual levels, could enable a better understanding of the mechanisms involved in this social gradient, and therefore, the development of targeted territorial actions to improve equity of access to healthcare.

Acknowledgements We gratefully acknowledge Sarah Ouanhnon for her translation help and her many advice. Many thanks to Hervé Mainsonneuve for his careful reading and his precious advice. We wish to thank all the members of the research team: Marine Maurel for her skills with R-software, Camille Joanes for her advice, and all the other members. The research team is supported by the French association 'La Ligue contre le cancer'.

Contributors L0: conceptualisation, methodology, formal analysis, funding acquisition, writing-original draft and review and editing, guarantor. CD: conceptualisation, methodology, formal analysis, supervision, validation, guarantor. PG: conceptualisation, data curation, methodology, formal analysis, supervision, validation, guarantor. MERB: conceptualisation, funding acquisition, validation. SL: methodology, formal analysis, writing-review, validation. VD: writing-review, validation. All authors read, edited and approved the final manuscript.

Funding This work was supported by Toulouse Hospital ('allocation jeune chercheur de la DRCl', Direction de la Recherche Clinique et de l'Innovation). There is no grant number: Toulouse Hospital allocates this grant to young doctors who wish to deepen their knowledge in research, after studying their research project.

Competing interests None declared.

Patient consent for publication Not applicable.

Ethics approval According to French registration, the ethics Committee approval is not applicable for this study (on pre-existing dataset).This study is conformed to the principles embodied in the Declaration of Helsinki. The authors obtained an agreement of the French National Institute of Health Data (INDS) and the permission from the 'Commission Nationale Informatique et Libertes' (CNIL) which is the French Data Protection Authority in accordance with Law No 78/17 of 6 January 1978 on computing, files and personal information, article 54, paragraph I. CNIL Authorisation: no. 1634837.

\section{Provenance and peer review Not commissioned; externally peer reviewed.}

Data availability statement Data may be obtained from a third party and are not publicly available. The procurement of such data necessitates the agreement of the French National Institute of Health Data (INDS) and the permission from the 'Commission Nationale Informatique et Liberte's (CNIL) which is the French Data Protection Authority in accordance with Law No 78/17 of 6 January 1978 on computing, files and personal information, article 54 , paragraph I. Data cannot be diffused without these authorisations. A CNIL Authorisation (no. 1634837) was obtained for our study. In addition, data cannot be shared with anyone who does not have these authorisations.

Supplemental material This content has been supplied by the author(s). It has not been vetted by BMJ Publishing Group Limited (BMJ) and may not have been peer-reviewed. Any opinions or recommendations discussed are solely those of the author(s) and are not endorsed by BMJ. BMJ disclaims all liability and responsibility arising from any reliance placed on the content. Where the content includes any translated material, BMJ does not warrant the accuracy and reliability of the translations (including but not limited to local regulations, clinical guidelines, terminology, drug names and drug dosages), and is not responsible for any error and/or omissions arising from translation and adaptation or otherwise.

Open access This is an open access article distributed in accordance with the Creative Commons Attribution Non Commercial (CC BY-NC 4.0) license, which permits others to distribute, remix, adapt, build upon this work non-commercially, and license their derivative works on different terms, provided the original work is properly cited, appropriate credit is given, any changes made indicated, and the use is non-commercial. See: http://creativecommons.org/licenses/by-nc/4.0/.

\section{ORCID iD}

Lisa Ouanhnon http://orcid.org/0000-0003-3361-057X
REFERENCES

1 International Agency for research on Cancer. Estimated number of deaths in 2020, breast, females, all ages: IARC Gobocan [Internet]. Available: https://gco.iarc.fr/today/online-analysis-table?v=2020\& mode $=$ population \&mode_population $=$ countries\&population $=900 \&$ populations $=900 \&$ key $=$ asr \&sex $=2 \&$ cancer $=20$ \&type $=1 \&$ statistic $=5 \&$ prevalence $=0 \&$ population_group=0\&ages_group $\% 5 \mathrm{~B} \% 5 \mathrm{D}=0 \&$ ages group $\% 5 B \% 5 D=17 \&$ group_cancer=1\&include_nmsc=1\&include_ nmsc_other $=1$

2 Institut National du Cancer. Le programme de dépistage organisé - Dépistage du cancer du sein [Internet]. cancer.fr, 2019. Available: https://www.e-cancer.fr/Professionnels-de-sante/Depistage-etdetection-precoce/Depistage-du-cancer-du-sein/Le-programme-dedepistage-organise

3 INCA. Le programme de dépistage organisé du cancer du col de l'utérus - Dépistage du cancer du col de l'utérus [Internet]. Available: https://www.e-cancer.fr/Professionnels-de-sante/Depistage-etdetection-precoce/Depistage-du-cancer-du-col-de-I-uterus/Leprogramme-de-depistage-organise

4 Santé publique France. Evaluation du programme de dépistage du cancer du col de l'utérus [Internet]. Available: http:// santepubliquefrance.fr/maladies-et-traumatismes/cancers/cancerdu-col-de-l-uterus/articles/evaluation-du-programme-de-depistagedu-cancer-du-col-de-l-uterus [Accessed 13 May 2020].

5 Poiseuil M, Coureau G, Payet C, et al. Deprivation and mass screening: survival of women diagnosed with breast cancer in France from 2008 to 2010. Cancer Epidemiol 2019;60:149-55.

6 Duport N, Serra D, Goulard H, et al. Quels facteurs influencent la pratique du dépistage des cancers féminins en France? Revue d'Épidémiologie et de Santé Publique 2008;56:303-13.

7 Grillo F, Vallée J, Chauvin P. Inequalities in cervical cancer screening for women with or without a regular consulting in primary care for gynaecological health, in Paris, France. Prev Med 2012;54:259-65.

8 Delpierre $\mathrm{C}$, Fantin $\mathrm{R}$, Chehoud $\mathrm{H}$, et al. Inégalités sociales d'accès aux soins et la prévention en Midi-Pyrénées, France, 2012, 2016. Available: http://invs.santepubliquefrance.fr//beh/2016/1/2016_1_1. html

9 Evans DB, Hsu J, Boerma T. Universal health coverage and universal access. Bull World Health Organ 2013;91:546-546A.

10 Thiede M, Akweongo P, Mclntyre D. Exploring the dimensions of access. In: Mclntyre D, Mooney G, eds. The Economics of Health Equity [Internet. Cambridge: Cambridge University Press, 2007: 103-23. https://www.cambridge.org/core/books/economicsof-health-equity/exploring-the-dimensions-of-access/684DFDF7 B640370D207C59FEAFC967E7

11 HCSP. Les systèmes d'information pour la santé publique. Paris: Haut Conseil de la Santé Publique, 2009. https://www.hcsp.fr/ explore.cgi/avisrapportsdomaine?clefr $=175$

12 Ducros D, Nicoules V, Chehoud H, et al. Les bases médicoadministratives pour mesurer les inégalités sociales de santé. Sante Publique 2015;27:383-94.

13 Pornet C, Delpierre C, Dejardin O, et al. Construction of an adaptable European transnational ecological deprivation index: the French version. J Epidemiol Community Health 2012;66:982-9.

14 Yang XY, Hu A, Schieman S. Relative deprivation in context: how contextual status homogeneity shapes the relationship between disadvantaged social status and health. Soc Sci Res 2019;81:157-69.

15 Barlet M, Coldefy M, Collin C, et al. L'Accessibilité potentielle localisée (APL) : une nouvelle mesure de l'accessibilité aux soins appliquée aux médecins généralistes libéraux en France [Internet]. Drees, 2012. Available: https://drees.solidarites-sante.gouv.fr/etudeset-statistiques/publications/documents-de-travail/serie-etudeset-recherche/article/l-accessibilite-potentielle-localisee-apl-unenouvelle-mesure-de-I

16 Short SE, Mollborn S. Social determinants and health behaviors: conceptual frames and empirical advances. Curr Opin Psychol 2015;5:78-84.

17 Chandak A, Nayar P, Lin G. Rural-Urban disparities in access to breast cancer screening: a spatial clustering analysis. J Rural Health 2019;35:229-35.

18 Orwat J, Caputo N, Key W, et al. Comparing rural and urban cervical and breast cancer screening rates in a privately insured population. Soc Work Public Health 2017;32:311-23.

19 Leung J, McKenzie S, Martin J, et al. Effect of rurality on screening for breast cancer: a systematic review and meta-analysis comparing mammography. Rural Remote Health 2014;14:2730.

20 INSEE (Institut National de la Statistique et des Etudes Economiques). Le nouveau zonage en aires urbaines de 2010 - Insee Première - 1374 [Internet], 2010. Available: https://www.insee.fr/fr/ statistiques/1281191 [Accessed 26 Nov 2021]. 
21 R Core Team. R: A language and environment for statistical computing. [Internet], 2013. Available: http://www.R-project.org/

22 Smith RA, Andrews KS, Brooks D, et al. Cancer screening in the United States, 2019: a review of current American cancer Society guidelines and current issues in cancer screening. CA Cancer J Clin 2019;69:184-210.

23 Dailey AB, Kasl SV, Holford TR, et al. Neighborhood-level socioeconomic predictors of nonadherence to mammography screening guidelines. Cancer Epidemiol Biomarkers Prev 2007;16:2293-303.

24 Dailey AB, Brumback BA, Livingston MD, et al. Area-level socioeconomic position and repeat mammography screening use: results from the 2005 National health interview survey. Cancer Epidemiol Biomarkers Prev 2011;20:2331-44.

25 Murfin J, Irvine F, Meechan-Rogers R, et al. Education, income and occupation and their influence on the uptake of cervical cancer prevention strategies: a systematic review. J Clin Nurs 2020;29:393-415.

26 Borràs JM, Sánchez V, Sánchez V, et al. Educational level, voluntary private health insurance and opportunistic cancer screening among women in Catalonia (Spain). Eur J Cancer Prev 1999;8:427-34.

27 Douglas E, Waller J, Duffy SW, et al. Socioeconomic inequalities in breast and cervical screening coverage in England: are we closing the gap? J Med Screen 2016;23:98-103.

28 Massat NJ, Douglas E, Waller J, et al. Variation in cervical and breast cancer screening coverage in England: a cross-sectiona analysis to characterise districts with atypical behaviour. BMJ Open 2015;5:e007735

29 Eisinger F, Viguier J, Touboul C, et al. Social stratification, risk factor prevalence and cancer screening attendance. Eur J Cancer Prev 2015;24 Suppl:S77-81.

30 Chauvin P, Parizot I. Les inégalités sociales et territoriales de santé dans l'agglomération parisienne. Une analyse de la cohorte Sirs (2005) [Internet]. Délégation interministérielle la Ville, 2009. Available: https://www.hal.inserm.fr/inserm-00415971 [Accessed 01 Jun 2020].
31 Deborde T, Chatignoux E, Quintin C, et al. Breast cancer screening programme participation and socioeconomic deprivation in France. Prev Med 2018;115:53-60.

32 Crockett R, Wilkinson TM, Marteau TM. Social patterning of screening uptake and the impact of facilitating informed choices: psychological and ethical analyses. Health Care Anal 2008;16:17-30.

33 Szarewski A, Cadman L, Ashdown-Barr L, et al. Exploring the acceptability of two self-sampling devices for human papillomavirus testing in the cervical screening context: a qualitative study of Muslim women in London. J Med Screen 2009;16:193-8.

34 Schueler KM, Chu PW, Smith-Bindman R. Factors associated with mammography utilization: a systematic quantitative review of the literature. J Womens Health 2008;17:1477-98.

35 Beaulieu MD, Béland F, Roy D, et al. Factors determining compliance with screening mammography. CMAJ 1996;154:1335-43.

36 Ouédraogo S, Dabakuyo-Yonli TS, Roussot A, et al. [Breast cancer screening in thirteen French departments]. Bull Cancer 2015;102:126-38.

37 Ouédraogo S, Dabakuyo-Yonli TS, Roussot A, et al. European transnational ecological deprivation index and participation in population-based breast cancer screening programmes in France. Prev Med 2014:63:103-8.

38 Cancer Care Ontario. Cancer Fact: Invitation letters improve breast screening behaviour [Internet], 2016. Available: https://www. cancercareontario.ca/en/cancer-facts/invitation-letters-improvebreast-screening-behaviour [Accessed 13 May 2020].

39 Everett T, Bryant A, Griffin MF, et al. Interventions targeted at women to encourage the uptake of cervical screening. Cochrane Database Syst Rev 2011;57.

40 Raginel T, de Mil R, Garnier A, et al. National organization of uterine cervical cancer screening and social inequality in France. Eur $J$ Cancer Prev 2020;29:458-65.

41 Autier P. [Screening for breast cancer: worries about its effectiveness]. Rev Prat 2013;63:1369-77. 